\title{
Vallaux Camille, Le sol et l'Etat 1911, nouvelle édition présentée par Jean-Pierre Villard
}

Paris, L'Hamarttan, 2017, 302 p.

Philippe Boulanger

\section{(2) OpenEdition}

Journals

Édition électronique

URL : https://journals.openedition.org/geohist/1386

DOI : 10.4000/geohist.1386

ISSN : 2264-2617

Éditeur

Association française de la Revue de géographie historique

Référence électronique

Philippe Boulanger, « Vallaux Camille, Le sol et l'Etat 7977, nouvelle édition présentée par Jean-Pierre Villard », Revue de géographie historique [En ligne], Comptes-rendus, mis en ligne le 20 novembre 2017 consulté le 12 juin 2021. URL : http://journals.openedition.org/geohist/1386 ; DOI : https://doi.org/ 10.4000/geohist.1386

Ce document a été généré automatiquement le 12 juin 2021.

\section{(i) $\odot$

$\mathrm{Ce}(\mathrm{tte})$ œuvre est mise à disposition selon les termes de la Licence Creative Commons Attribution Pas d'Utilisation Commerciale - Pas de Modification 4.0 International. 


\section{Vallaux Camille, Le sol et l'Etat 1911, nouvelle édition présentée par Jean- Pierre Villard}

Paris, L'Hamarttan, 2017, 302 p.

\section{Philippe Boulanger}

\section{RÉFÉRENCE}

Vallaux Camille, Le sol et l'Etat 1911, nouvelle édition présentée par Jean-Pierre Villard, Paris, L’Hamarttan, 2017, 302 p.

\section{NOTE DE L'ÉDITEUR}

PS : Ce compte rendu a fait l'objet d'une première publication dans la revue $L a$

Géographie, n¹567, nov-dec. 2017.

1 Disciple de Vidal de la Blache et auteur d'une thèse de doctorat sur la Basse Bretagne, étude de géographie humaine, Camille Vallaux (1870-1945) est plus connu pour ses nombreux travaux sur les régions océaniques de l'Europe du Nord-Ouest, l'océanographie et l'hydrologie marine. Les récents travaux de Marc Levatois (2013) ont montré son important apport dans la géographie maritime française dont La Mer(1908) constitue une œuvre centrale.

2 Il est aussi considéré comme l'un des pionniers de la géographie politique française (notamment en rapport avec la géographie maritime) qui manque toutefois de s'imposer dans le milieu universitaire dans la première moitié du XXe siècle. Comme le souligne l'avant-propos présenté par Jean-Pierre Villard, riche et analytique (34 pages), «on ne peut être surpris de l'oubli dans lequel est tombé Camille Vallaux aujourd'hui». A l'exception d'une notice publiée par François Carré en 1973, nous savons peu de ce 
géographe qui s'est intéressé à la manière de penser le territoire en politique. Dans Géographie sociale: le sol et l'Etat, qui n'avait pas été réédité depuis 1911, nous redécouvrons un "texte fondateur de la géographie politique» qui s'inscrit dans un contexte intellectuel spécifique. Face à la théorisation de l'espace du géographe allemand Friedrich Ratzel, présentée dans Politische Geographie en 1897, Camille Vallaux propose une autre manière de considérer la géographie politique. Il s'oppose au déterminisme naturel promu par son prédécesseur allemand, critique vivement la notion d'espace (Raum) et de position (Lage). Il propose une géographie politique plus ouverte sur les dynamiques économiques et sociales, sur les conditions les plus favorables à la formation des Etats (notion de la différenciation), sur la place des frontières dans la croissance des activités humaines (dont l'originalité est rarement citée). Cette réédition du Sol et de l'Etat, introuvable dans les librairies spécialisées, ne manquera pas d'intéresser historiens et géographes férus de pensée géographique. 